\title{
Diagnosis of COVID-19 by Bronchoalveolar Lavage after Two Negative Nasopharyngeal Swabs
}

Victoria Chuen, Hosay Said, Jaymee R Shell, William R Plaxton, William R Ciccotelli

\author{
About the Authors \\ Victoria Chuen, Hosay Said, Jaymee Shell, William Plaxton, and William Chccotelli are all with the Department of Medicine, McMaster \\ University, Hamilton, Ontario, Canada and the Waterloo Regional Campus, McMaster University, Kitchener, Ontario, Canada. \\ William Ciccotelli is also with the Department of Medicine, Division of Pathology and Molecular Medicine, McMaster University, \\ Hamilton, Ontario, Canada and the Department of Infectious Disease and Medical Microbiology, Grand River Hospital, Kitchener, \\ Ontario, Canada. \\ Corresponding author: jaymee.shell@medportal.ca \\ Submitted: April 6, 2020. Accepted: April 7, 2020. Published: April 8, 2020 ahead of issue. DOI: 10.22374/cjgim.v15i2.449
}

\begin{abstract}
This case report highlights the diagnostic limitations of nasopharyngeal swabs in diagnosing COVID-19. This patient had a positive travel history, typical symptoms (fever, dry cough, dyspnea) and two negative nasopharyngeal swabs (NPS). He deteriorated clinically and required intubation. After intubation, bronchoalveolar lavage was used to sample the lower respiratory tract, which confirmed the diagnosis of COVID-19. This case demonstrates the diagnostic limitation of reliance on nasopharyngeal swab PCR alone for the diagnosis of COVID-19. NPS tests may result in false negatives with incorrect sampling technique or if the sampling is done while the upper tract viral load is low, such as very early or late during the illness course. During this pandemic, we posit that clinicians should maintain a high degree of suspicion based on supportive clinical findings despite negative PCR testing as this has implications for hospital infection control procedures.
\end{abstract}

\section{Resume}

Ce rapport de cas met en évidence les limites diagnostiques des écouvillons nasopharyngés dans le diagnostic de la COVID-19. Ce patient avait des antécédents de voyage positifs, des symptômes typiques (fièvre, toux sèche, dyspnée) et deux écouvillons nasopharyngés négatifs (NPS). Son état clinique s'est détérioré et a nécessité une intubation. Après l'intubation, un lavage bronchoalvéolaire a été utilisé pour prélever un échantillon des voies respiratoires inférieures, ce qui a confirmé le diagnostic de COVID-19. Ce cas démontre les limites diagnostiques de la seule utilisation de la PCR sur écouvillon nasopharyngé pour le diagnostic de la COVID-19. Les tests NPS peuvent donner des faux négatifs si la technique de prélèvement est incorrecte ou si le prélèvement est effectué alors que la charge virale des voies supérieures est faible, par exemple très tôt ou très tard dans lévolution de la maladie. Pendant cette pandémie, nous posons comme principe que les cliniciens doivent maintenir un haut degré de suspicion basé sur des résultats cliniques favorables malgré des tests PCR négatifs, car cela a des implications pour les procédures de contrôle des infections hospitalières. 


\section{Background}

COVID-19 is a pandemic driven by a rapidly spreading, severe respiratory illness caused by a novel coronavirus: SARS-CoV2.

Polymerase chain reaction (PCR) for SARS-CoV2 using nasopharyngeal swabs (NPS) samples is the current standard for diagnosis diagnosis. ${ }^{1}$ Assessment of the World Health Organization's PCR assays demonstrated high specificity (100\%), and sensitivity of $61--68 \%$, which increases to $71-79 \%$ with repeated testing testing. ${ }^{2}$ In one study, 33\% of suspected COVID-19 patients with negative PCR testing had computed tomography (CT) findings consistent with COVID-193.19. ${ }^{3}$ Others concluded COVID-19 could not be reliably diagnosed using PCR alone, given its low sensitivity, ${ }^{4}$ which is affected by the time of sampling relative to onset of (i.e., when viral shedding, correct sampling technique and assays with a poor limit of detection. In an analysis of site sampling, lower respiratory tract samples were positive more often than NPS. However, testing in this study is biased towards severely ill, intubated patients, where endotracheal tube sampling is feasible. ${ }^{1}$

There is only one published report of COVID-19 diagnosed with bronchoalveolar lavage (BAL) after numerous negative.NPS. ${ }^{5}$ We report what we believe is the first case in North America.

\section{Objective}

To alert clinicians to maintain a high suspicion for COVID-19 in the appropriate clinical context, despite recurrent negative NPS testing and to highlight potential difficulties in removing isolation precautions in the intensive care unit (ICU).

\section{Case Report:}

A 54-year-old male with a history of gout travelled from Canada to the United States from February 29th-March 1st, 2020. Twelve days after, he developed persistent fevers, myalgias, dyspnea, a dry cough, nausea, and vomiting. On symptom day 5 , his family physician ordered a chest $\mathrm{x}$-ray, which was normal. Treatment with amoxicillin-clavulanate offered no improvement. $\mathrm{He}$ presented to the emergency department on symptom day 7 .

At presentation, he was afebrile; his oxygen saturation was $93 \%$ on $2 \mathrm{~L}$ of oxygen via nasal prongs. Chest $\mathrm{x}$-ray demonstrated new bilateral, peripheral airspace opacities. Initial blood work demonstrated lymphopenia $\left(0.6 \times 10^{9} \mathrm{~L}\right)$, hyponatremia $(134$ $\mathrm{mmol} / \mathrm{L}$ ), normal liver enzymes and elevated inflammatory markers (c-reactive protein $137 \mathrm{mg} / \mathrm{L}$, lactate dehydrogenase 965 IU/L). Urine legionella antigen and NPS for SARSCoV2, influenza A, influenza B, respiratory syncytial virus, metapneumovirus, parainfluenza types 1 and 3, adenovirus, rhinovirus and enterovirus were sent. He was admitted to the medical ward and started on ceftriaxone and azithromycin for possible community-acquired pneumonia.
On symptom day 8 , he was transferred to the ICU for hypoxemic respiratory failure, initially managed with a high-flow nasal cannula (50L50 L/min, FiO2 80\%). The initial nasopharyngeal swab (NPS) was negative for all respiratory viruses, including SARS-CoV2. Another swab was sent given the high index of suspicion. By symptom day 10, he was intubated. The repeat NPS was negative.

His subsequent laboratory investigations demonstrated persistent lymphopenia, transaminitis (aspartate aminotransferase $63 \mathrm{IU} / \mathrm{L}$, alanine aminotransferase $51 \mathrm{IU} / \mathrm{L}$, alkaline phosphatase level 144 IU/L, gama-glutamyl transferase $310 \mathrm{IU} / \mathrm{L}$ ), hyperbilirubinemia $40 \mathrm{umol} / \mathrm{L}, \mathrm{c}$-reactive protein $299 \mathrm{mg} / \mathrm{L}$, lactate dehydrogenase $972 \mathrm{IU} / \mathrm{L}$ and ferritin $1020 \mathrm{ug} / \mathrm{L}$. A workup for infectious, malignant and autoimmune etiologies for acute respiratory distress syndrome were all negative. An abdominal/pelvic CT demonstrated no intra-abdominal abnormalities, but identified lung findings consistent with COVID-19, including bilateral pleural effusions, atelectasis vs. consolidation, and crazy-paving (Figure 1). Subsequently, bronchoscopy and BAL was performed. BAL was positive for SARS-CoV2.

\section{Discussion}

Our case demonstrates that despite negative NPS for SARS-CoV2, clinicians should maintain a high degree of suspicion, given the patient's history, clinical trajectory, and CT findings. Our polymerase chain reaction assay has excellent sensitivity (95\%)

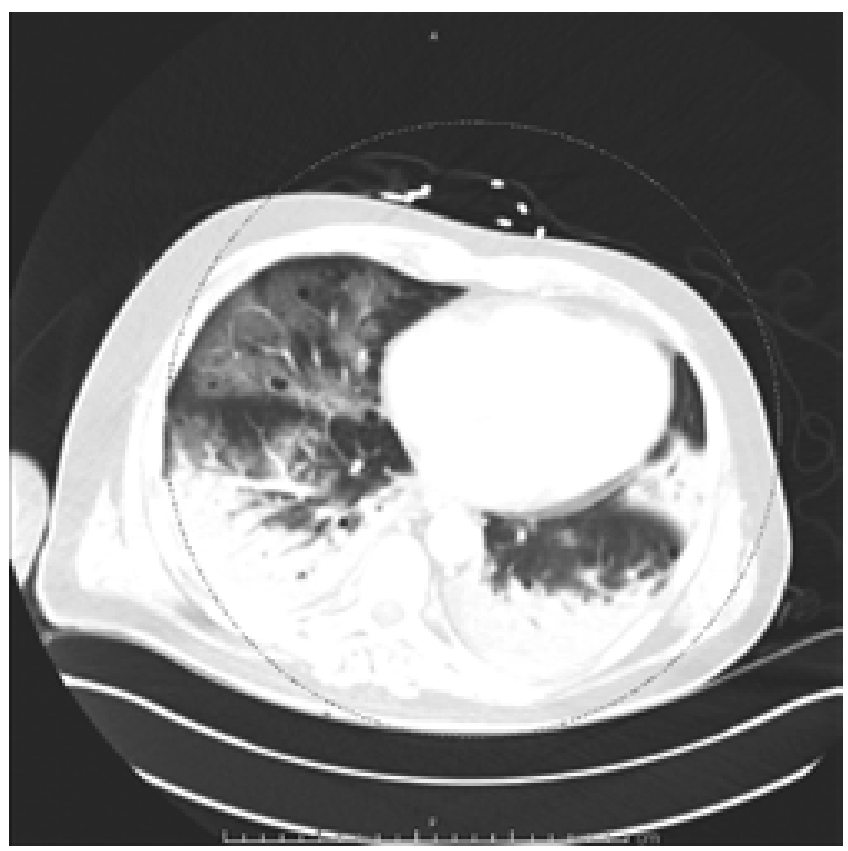

Figure 1. Lower lung zones captured on computed tomography of the abdomen/ pelvis demonstrating bilateral pleural effusions, atelectasis vs. consolidation, and crazy-paving. 
and specificity (100\%) for SARS-CoV2. This, however, relies on adequate viral load and proper sampling technique. We believe our patient's nasopharyngeal viral load had likely resolved by the time of NPS sampling, explaining the false negative results.

Given the consequences of false negative tests, a multimodal approach to the diagnosis of COVID-19 is favourable, especially in critically ill patients.

While BAL confirmed the diagnosis and assessed for comorbidities, it is an aerosolizing procedure and should be performed at the clinician's discretion. In intubated patients, endotracheal tube aspiration offers a non-aerosol generating alternative for sampling the lower airways.

Therefore, when the clinical suspicion for COVID-19 remains high despite negative NPS testing, infection control precautions should remain for patient and healthcare provider safety. Furthermore, NPS results may not be reliably used as a test of cure in the context of previously false negative results. This has implications on resource allocation and must be considered when removing isolation precautions.

\section{Disclosure}

All authors contributed equally to this work.

The authors disclose no conflicts of interest.

\section{References}

1. Wang W, Xu Y, Gao R, et al. Detection of SARS-CoV-2 in different types of clinical specimens. JAMA 2020 Mar 11;

2. Yam WC, Chan KH, Poon LLM, et al. Evaluation of reverse transcription-PCR assays for rapid diagnosis of severe acute respiratory syndrome associated with a novel coronavirus. J Clin Microbiol 2003 Oct;41(10):4521-4.

3. Ai T, Yang Z, Hou H, et al. Correlation of chest CT and rt-pcr testing in coronavirus disease 2019 (COVID-19) in China: A report of 1014 cases. Radiology 2020 Feb 26;200642.

4. Xie C, Jiang L, Huang G, et al. Comparison of different samples for 2019 novel coronavirus detection by nucleic acid amplification tests. Int J Infect Dis IJID Off Publ Int Soc Infect Dis 2020 Feb 27;93:264-7.

5. Ruan Z-R, Gong P, Han W, et al. A case of 2019 novel coronavirus infected pneumonia with twice negative 2019-nCoV nucleic acid testing within 8 days. Chin Med J (Engl) 2020 Mar 5;1. 